\title{
Las investigaciones en Cuba acerca de LGBTI. Posibilidades de incursión desde la comunicación
}

\author{
Investigations in Cuba about Lesbians, Gays, Bisexuals, Transsexuals \\ and Intersex. Opportunities of incursion from communication
}

María de las Mercedes Rodríguez Puzo

Centro Loyola/ Centro de Estudios Sociales Cubanos y Caribeños José Antonio Portuondo; Universidad de Oriente (Cuba)

\section{Resumen}

¿Cómo se han desarrollado las investigaciones académicas en Cuba sobre personas lesbianas, gays, bisexuales, transexuales e intersexuales? Es el interrogante que da pie al presente artículo, el cual tiene como objetivo describir la trayectoria de dichos estudios, partiendo del análisis de contenido y la revisión bibliográfica-documental. Su principal resultado es la sistematización de la evolución de las investigaciones sociológicas, literarias, historiográficas, psicológicas, médicas, teológicas y en especial las comunicológicas en torno a LGBTI, un tema poco tratado dentro de las ciencias sociales y humanísticas cubanas. A la vez, 
ofrece las posibilidades de corregir en el presente y a futuro los errores del pasado y eliminar concepciones machistas y sexistas. También señala las pautas para un discurso mediático que promueva la equidad y el respeto a la vida.

Palabras claves: LGBTI; investigaciones cubanas.

\section{Abstract}

How have been the cubans investigations on communication about lesbians, gays, bisexuals, transsexuals and intersex developed? It is the question that gives reason to the present article, which has like objective to describe the trajectory of the above-mentioned studies, departing of the Analysis of contents and the bibliographic documentary revision. The main result is the systematization of evolution of the investigations on sociology, literary, history, psichology, medicine, theology and specially on communication about LGBTI, a theme little treated in the social and humanists cubans sciences. At the same time, it offers the possibilities to correct in the present and future the errors of the past and eliminating macho and sexist conceptions. Also is able to indicate the guidelines for a massmedia speech that promotes equity and respect to life.

Keywords: LGBTI; cubans investigations.

Aparentemente las temáticas relacionadas con lesbianas, gays, bisexuales, transexuales e intersexuales (LGBTI) han sido un tabú en la prensa y en la literatura cubanas. Decimos "aparentemente" porque al escudriñar en archivos históricos, bibliotecas, hemerotecas e internet encontramos textos de diversas épocas referidos a las orientaciones e identidades sexuales diferentes a la heterosexual. El presente artículo propone describir la trayectoria de las investigaciones sociológicas, literarias, historiográficas, psicológicas, médicas, teológicas y de manera especial las comunicológicas en torno a LGBTI.

Entre los primeros podemos citar las crónicas de Gonzalo Fernández de Oviedo, que datan de 1535 y están recogidas en su Historia General y Natural de Las Indias. En sus diarios, Oviedo indica que la homosexualidad masculina era algo generalizado en las Antillas:

Entre los indios es muy común el pecado nefando contra natura. Son, en muchas partes, los de tierra firme, los indios sodomitas e públicamente los indios que son señores e principales que en esto pecan, tienen mozos con quien usan este maldito pecado, e los 
tales mozos pazientes, así como caen en esta culpa luego se ponen naguas como mujeres (Mott, 2001: 126).

El 10 de abril de 1791 apareció en el Papel Periódico de La Habana un artículo que quizás sea el primero en analizar y condenar los varones homosexuales cubanos, titulado Carta crítica del hombre-muger. El autor firma a través de un seudónimo, El amante del periódico, y al parecer se trata del sacerdote José Agustín Caballero. Impregnado de todo el machismo de la sociedad colonial, identifica la problemática de la masculinidad con la de la homosexualidad, incluso vincula la feminización de los hombres con actitudes en contra de la patria. El siguiente fragmento ilustra:

\begin{abstract}
¿Quién podrá contener la risa cuando ve a un hombre barbado gastar la mayor parte de una mañana en peinarse, ataviarse y en ver copiada su hermosura en un espejo, cual lo practica la dama más presumida? (...) a la verdad, yo no sé cómo hay Muger que admita a su trato a semejantes avechuchos. Ellos representan el papel de Gallos entre las Mugeres, y de Gallinas entre los Hombres, al paso que de estos merecen la compasión, cuando de aquellas el desprecio (El amante del periódico, 1791: 3)
\end{abstract}

Las mismas opiniones negativas contra homosexuales y transexuales se promulgaron desde la ciencia médica -igual ocurrió en el contexto internacional-, a cargo del Doctor Luis Montané. En 1890, durante el primer Congreso Médico Regional, el galeno presentó su ponencia "La pederastia en Cuba", a partir del estudio antropológico físico y social de veintiún casos (cuatro europeos y diecisiete cubanos). La imagen de trastornados mentales y depravados sexuales que transmite de los homosexuales masculinos, incidió en la interiorización distorsionada de sus prácticas sexuales y en los procesos de exclusión. Este trabajo constituye el primer intento serio -con marcadas limitaciones, claro- de abordar las disidencias sexuales por parte de la medicina cubana.

La Iglesia católica expresaba su rechazo a través de postulados androcéntricos justificados teológicamente en los textos bíblicos de Sodoma y Gomorra, Levítico 18:22, entre otros; los escritos científicos de la época estaban limitados por esas mismas concepciones religiosas; y el derecho contemplaba la homosexualidad como una figura delictiva y redefinía el concepto de "contra natura" para los transgresores de las normas sexuales establecidas.

En 1978 el economista Manuel Moreno Fraginals publicó el libro El Ingenio, complejo económico social cubano del azúcar. Siguiendo una depurada técnica historiográfica, nos remonta a las plantaciones esclavistas durante el boom azucarero del siglo XIX. En un acápite nombrado "Sexo y Producción", el investigador plantea: "La grave desproporción entre hombres y mujeres debió crear un tenso clímax de represión, canalizada hacia la masturbación, la homosexualidad y a una obsesión sexual que se expresó en mil formas: cuentos, juegos, 
cantos, bailes" (1978: 38). Para Moreno las relaciones homosexuales entre los esclavos son un mero resultado de la carencia de mujeres.

Durante décadas, la familia cubana descendiente de la española, machista y permeada de prejuicios religiosos, continuó reproduciendo su esquema patriarcal, enraizado de valores sexistas, incidiendo negativamente en la actitud hacia la homosexualidad. Al respecto Fidel Castro apunta que

El rechazo a la homosexualidad forma parte de la idiosincrasia de nuestro pueblo, que tiene orígenes múltiples desde la influencia árabe en España, hasta otras influencias de los propios españoles y tiene que ver con la forma de juzgar las relaciones sexuales de hombres y mujeres (1992: 4).

Escritos similares a Carta crítica del hombre-muger, homofóbicos y cargados de prejuicios sexistas, aparecieron a lo largo de la Colonia y fueron heredados por las publicaciones periódicas de la República neocolonial, dígase: Brisas de Cuba, El Artista, Biblioteca Selecta de Amena Instrucción, Prensa Universal, Diario de Cuba, etcétera.

El triunfo de la Revolución en 1959 marcó un punto de giro en la historia de Cuba. El país inició un período de cambios radicales en función de la justicia social y la tenencia de derechos. Sin embargo, aquellas personas consideradas de influencia negativa para el incipiente modelo de construcción socialista: homosexuales, hippies, religiosos y contrarrevolucionarios, fueron enviadas a las Unidades militares de apoyo a la producción para corregir su estilo de vida inadecuado. Pero la discriminación no quedó ahí, también se aplicó la "parametración", proceso en el que se analizaban a las personas que no cumplían los parámetros establecidos por las resoluciones del Primer Congreso de Educación y Cultura de 1971, cuyo resultado frecuente era la separación o traslado del centro escolar o laboral. La "parametración" tuvo su reflejo jurídico al aprobarse la Ley 1267 (1), portadora del siguiente inciso:

\footnotetext{
Sobre homosexualismo ostensible y otras conductas socialmente reprobables que proyectándose públicamente inciden nocivamente en la educación, conciencia y sentimiento públicos y en especial en la niñez y la juventud por parte de quienes desarrollen actividades culturales o artístico-recreativas desde centros de exhibición o difusión (Hernández, 2006: 15).
}

En contraposición, a partir de los setenta se creó un conjunto de grupos e instituciones sociales como el Grupo Nacional de Trabajo de Educación Sexual en 1972; la Sociedad Cubana Multidisciplinaria de Educación Sexual en 1985; el Grupo Operativo para el Enfrentamiento al VIH en 1986 y el Centro Nacional de Educación Sexual (CENESEX) en 1989, que generaron y promovieron una cosmovisión favorable al tratamiento de la sexualidad y socializaron las bases 
científicas de la educación sexual a la población. En esos años circuló en el contexto nacional el libro El hombre y la mujer en la intimidad, de Siegfried Schnabel, que divulgaba algunos avances científicos sobre la homosexualidad.

La desaparición de la Unión de Repúblicas Socialistas Soviéticas y el recrudecimiento del bloqueo económico impuesto por Estados Unidos a Cuba conllevaron, en los noventa, a transformaciones socioeconómicas y políticas en nuestro país, como una mayor apertura al turismo internacional, lo que propició la difusión de nuevas ideas a favor de la homosexualidad, que ponían en tela de juicio los prejuicios, incomprensiones y tabúes construidos desde el imaginario social. Estas, junto a la influencia y los avances del movimiento feminista a nivel mundial y de manera especial en América Latina, más las victorias en la lucha por los derechos de LGBTI y el tratamiento favorable que estaba recibiendo entonces la homosexualidad en el ámbito internacional, repercutieron dentro de la producción académica cubana. Súmese el rol desempeñado por la literatura -ejemplo de ello son las publicaciones de los poemas Vestido de novia y Desnudo frente a la ventana-; y por el cine, con el positivo impacto del filme Fresa $y$ Chocolate, en 1993.

A finales de los noventa comenzaron a realizarse investigaciones desde la historiografía, la sociología, la psicología, la medicina y la filosofía, que pretenden describir las construcciones sociales en torno a la masculinidad y prestan atención a las actitudes heterosexuales frente a la población homosexual masculina. Los estudiosos que incursionan en el tema son portavoces de los resultados científicos alcanzados en Estados Unidos y Europa.

Víctor Fowler es un autor destacado en dicha etapa. A través de su obra La maldición: una historia del placer como conquista, publicada en 1998, nos acerca al asunto desde una perspectiva histórico-literaria. Fowler aborda varios textos considerados por él fundacionales, dado que corresponden a un período de constitución de nuestra cultura y trazan las pautas de lo que será más tarde el patrón de familia heterosexual que se desea para la isla.

De la Universidad de Oriente sobresale en ese año el Trabajo de Diploma "Estudio del imaginario social de la masculinidad en hombres jóvenes", realizado por dos estudiantes de psicología, Gabriel Taybo y Armando González. Dicha investigación plantea que:

\footnotetext{
Las actitudes homofóbicas se manifiestan con persistencia ante la posible generación de alguna duda de la virilidad que con orgullo exhiben. Tienen lugar expresiones orales que con tonos despectivos ridiculizan la homosexualidad y a los homosexuales. En los más jóvenes se presenta tolerancia hacia estos y los consideran también hombres, aunque lo instituido les impide establecer relaciones desprejuiciadas con ellos (Taybo y González, 1998: 42).
} 
En 1999 Felipe Pérez Cruz con su libro Homosexualidad, homosexualismo y ética humanista marca un punto de giro en la investigación; se enmarca en la homosexualidad manifiesta o neta. Revisa explicaciones científicas de la conducta homosexual, su etiología, clasificaciones en las diferentes épocas y contextos socioeconómicos. Consideramos que con el siguiente planteamiento pone los puntos sobre las íes a una problemática que se extiende hasta hoy:

\begin{abstract}
La dirección principal de las investigaciones -como se puede observar- se centra en el problema psicofisiológico, en la relación entre homosexualidad e individuo. La relación entre homosexualidad y sociedad no ha sido atendida con suficiencia. Hasta donde se conoce, el ángulo praxiólogico-valorativo ha estado ausente de la indagación científica (Pérez Cruz, 1999: 30).
\end{abstract}

El siglo XXI trae consigo una evolución en el abordaje de temas relacionados con LGBTI desde diversas disciplinas, temas que incluyen a los medios de comunicación y su influencia en la construcción del imaginario social. A decir de Mariela Castro:

\begin{abstract}
Con la creación del CENESEX se ampliaron y profundizaron las bases científicas de la educación sexual y comenzó la introducción del enfoque de género como eje transversal del Programa Nacional de Educación Sexual. En el año 2000, surge el proyecto de Prevención de SIDA en HSH, para la capacitación de sus integrantes como promotores y consejeros de salud, y para la realización de acciones de prevención social. En este escenario, el CENESEX ejerció influencias en la visibilidad de la homosexualidad, dirigiendo la mirada hacia los estudios de la misma, y en 2004, reorganizó su estrategia institucional e introdujo como prioridad los temas relacionados con la diversidad sexual. En 2005, se abordó la diversidad sexual con enfoque de derechos humanos en el país (2014: 84).
\end{abstract}

Acontece aquí un posicionamiento de la investigación sociológica, desde la incursión de Luis Robledo en el 2000, quien se propuso caracterizar algunos aspectos de la relación homosexualidad-familia. En su Tesis de Maestría "Homosexualidad-familia. Acoso y simetrías", muestra a un grupo de homosexuales varones que emigran a la capital al haber sufrido situaciones de exclusión social en sus provincias de origen. Ubica tales situaciones en tres ámbitos: familiar, socio comunitario y socio institucional. Enuncia que el ámbito comunitario es un espacio donde están fuertemente fijadas las expectativas y prácticas cotidianas sobre la base de las tradicionales nociones de la construcción de género. Alude, además, a la exclusión jurídica que padece la pareja homosexual, dada en la imposibilidad de matrimonio y adopción. Interesado en descifrar algunas claves del sexismo en la Cuba del antepasado siglo, Abel Sierra Madero nos lega en 2002 su libro La nación sexuada, que contiene un capítulo titulado El sexismo orientado hacia los homosexuales. La homosexualidad masculina y la femenina son reflejadas aquí a través de una exhaustiva y crítica revisión de la prensa, archivos, documentos 
penales y códigos de vida de la época. Como una continuación de este texto, podría considerarse La policía del sexo: la homofobia durante el siglo XIX en Cuba, publicado al año siguiente. Ambos libros dotan a nuestra investigación de una amplia historiografía que permite entender los antecedentes de la homofobia internalizada en la sociedad cubana actual.

Literatura de referencia obligada es la producción del Doctor Julio César González Pagés, con valiosos textos como Género y masculinidad en Cuba: ¿el otro lado de una historia? (2002), Homosexualidad, feminismo, travestismo y construcción de la masculinidad en Cuba (2003), Feminismo y masculinidad. ¿Mujeres contra hombres? (2004), Macho, varón, masculino. Estudios de masculinidades en Cuba (2010) y Vestida de hombre (2012). El autor ha abordado la influencia del legado histórico cultural en la configuración del modelo hegemónico de masculinidad, así como la definición de espacios vitales de socialización de esta ideología en la actualidad. Fue él quien incorporó el término "masculinidades" en el discurso científico nacional.

En mayor y menor medida, a través de sus obras antes mencionadas Pagés revela cómo se ha construido una nación excluyente de los homosexuales, siendo el tema de las homosexualidades una de las zonas de silencio. Según él, la homosexualidad se trata en términos de acto discriminatorio en su movimiento en el tiempo, desde la época de la colonia hasta hoy, ofreciendo evidencias de la transformación de las representaciones de la sociedad al respecto y el impacto de las diferentes manifestaciones artísticas. Vestida de hombre recoge la historia de Enriqueta Fabert, la cirujana que se hizo pasar por hombre en la ciudad de Baracoa y contrajo matrimonio con Juana de León en 1819.

La periodista Isabel Moya propone el artículo Lo gay también vende, donde profundiza en la publicidad internacional y las estrategias de ventas para el público homosexual masculino. Señala que

\footnotetext{
Para perpetuarse, la ideología y el poder patriarcales hegemónicos optan por metamorfosearse, puede parecer que ceden terreno, pero desde lo simbólico manipulan y articulan estructuras que inciden en la configuración del imaginario colectivo para aparentar una asimilación de la diversidad sexual, cuando en realidad, a partir de un tratamiento sesgado continúan perpetuando el prejuicio de lo "anormal (Moya, 2004: 20).
}

Y agrega: "en las agencias publicitarias cubanas no es práctica profesional recurrir a la temática homosexual, pues consideran que crearía rechazo en las audiencias (Idem).

Casi como una excepción de la regla aparece el libro La sexualidad en el misterio del ser humano, del Reverendo Raimundo García Franco, quien logra desprenderse de una lectura literal de la Biblia y de dogmas religiosos y prejuicios conservadores para analizar la diversidad sexual desde una óptica liberadora y con ojos de verdadero amor hacia el prójimo. Llama la atención que Raimundo es de los primeros investigadores en utilizar el término diversidad 
sexual e incluir en su estudio a lesbianas, bisexuales y transexuales, tanto masculinos como femeninos. El pastor bautista plantea:

\begin{abstract}
Yo no voy a negar que la Biblia tiene palabras de condenación para lo que no es heterosexual, pero al mismo tiempo jhay tantas condenaciones para nosotros, los heterosexuales, y por muchas diferentes razones! El rechazo social en el cual ha participado la Iglesia contra los no heterosexuales los ha incluido en la categoría de escorias, delincuentes, corrompidos... y esto mancha, perturba, deforma. Pero seguimos haciéndolos culpables a ellos de tantas cosas. ¿Culpables de qué?, ¿de haber nacido con esa tendencia o de haber sido inclinados por una u otra razón a esa tendencia? Nosotros, ¿no somos culpables de haberlos excluido y de haberlos tratado como basura? (García
\end{abstract} Franco, 2007: 105).

La educación de la sexualidad en un mundo mediático. Reflexiones desde Cuba, es un artículo escrito por Carolina Díaz Bravo y resulta una provocación a nuestro tema de investigación, pues invita a pensar qué ha ocurrido con las subjetividades, especialmente en lo referido a la sexualidad, tras la aparición de productos comunicativos como los filmes Retrato de Teresa y Fresa y Chocolate, la telenovela La otra cara de la luna, y el espacio "Sexo Sentido" del periódico Juventud Rebelde. La especialista plantea que

\begin{abstract}
un análisis de los medios pondría al descubierto proposiciones explícitas o implícitas relativas a ideales sexuales que generalmente refuerzan la eficacia y la rapidez y restan trascendencia a la comunicación. (...) Los mensajes sobre sexualidad contenidos en dichos medios pasan a formar parte de los aprendizajes no formales de los receptores (Díaz Bravo, 2007: 29).
\end{abstract}

A partir del empleo del método de historia de vida, Maribel Rodríguez Cárdenas realizó en 2008 su Trabajo de Diploma "La socialización de varones homosexuales. Un estudio de caso en Santa Clara" y llegó a varias conclusiones interesantes sobre la influencia de los diferentes espacios (privados y públicos) en la socialización de estos individuos, que permiten conocer la dinámica homosexual en el territorio analizado.

El artículo Diversidad sexual en las políticas públicas en Cuba: avances y desafíos, del médico y activista LGTBI Alberto Roque (2011), revela con nitidez la voluntad política para buscar soluciones a las situaciones de desigualdad, diferenciación o exclusión social que padecen los homosexuales, desde el accionar de algunas instituciones como el CENESEX. Lamentablemente, su autor no repara en la implicación del resto de los actores o agentes sociales de inclusión que pueden generar cambios en el proceso de construcción colectiva.

Bajo el título Estudios sobre sexualidad y género: su visualización en la revista Sexología y Sociedad (2), la socióloga Yenisei Bombino Companioni realizó un análisis cuanti-cualitativo en 
aras de valorar el proceso de inclusión de la perspectiva de género en los temas publicados. Partiendo del análisis del discurso y la teoría de usos y representaciones sociales, ella revela que:

En 1997 la revista publicó el primer artículo sobre homosexualidad, Homosexualidad egodistónica, del peruano Artidoro Cáceres, y en 2002 aparece el artículo Prevención del VIH entre HSH, del cubano Leonardo Chacón. (...) El sector más representado son los gays, vinculados a temáticas relacionadas con la prevención del $\mathrm{VIH} / \mathrm{Sida}$, las representaciones sociales y el comportamiento sexual de la población homosexual masculina. No se identificaron estudios sobre las necesidades de salud sexual y reproductiva, así como la identidad grupal y sociosexual de la población lésbica, pues este grupo se diluye en los análisis de los derechos de las poblaciones LGBT (Bombino, 2013: 28).

En 2013, Roxana Moreno Castañeda presentó el Trabajo de Diploma "Ni vigilar ni castigar: un análisis del discurso en la revista Sexología y Sociedad". La estudiante de Periodismo toma una decena de ejemplares como muestra para determinar géneros periodísticos, temas más frecuentes y conceptos claves de esta publicación, partiendo del enfoque de género. Como bien declara en el título, el informe no asume una postura crítica ante el escaso tratamiento de tópicos relacionados con lesbianas y mujeres transexuales.

Siguiendo con Sexología y Sociedad, en su número 51 publicó nueve artículos de prensa relacionados con la VI Jornada contra la Homofobia. Sara Más, Dixie Edith y Helen Hernández Hormilla son las autoras de noticias y comentarios que abogan por la aceptación familiar y social junto al reconocimiento de derechos específicos que amparen la dignidad humana de LGBTI y legitimen identidades diversas.

Como complementación a los antecedentes se encuentra el artículo Homosexuales en la ciudad Santiaguera. Un enfoque de análisis desde la Sociología. Su autora es la socióloga Yamirka Robert Brady, pionera en aportar una caracterización de elementos internos y externos de la población homosexual en el territorio, su relación con el entorno social, vestuarios, comportamientos, sitios de encuentro.

El prestigioso investigador Ramón Rivero Pino es una muestra de la evolución del pensamiento académico actual, en su compilación Pensar las masculinidades nos invita a hacerlo con enfoque de género e incluye en su análisis a las orientaciones no heteronormativas. Entre sus principales planteamientos hallamos:

La homosexualidad, tanto masculina como femenina, produce aún en nuestra sociedad una gran alarma y continúa siendo un tema que ruboriza a la mayoría de las personas. Esta temática se trata con eufemismos o simplemente no se trata; cuando se aborda, la mayoría de las veces se hace sobre la base de los prejuicios y la exclusión. Si analizamos este tipo 
de orientación sexual desde la perspectiva de las relaciones de género y sexo, podemos afirmar, sin dudas, que hacia estas personas la sociedad se manifiesta mediante el rechazo y la segregación (Rivero Pino, 2014: 6).

Justo en Pensar las masculinidades aparece un texto revelador para nuestro tema de estudio. Roberto Carlos Delgado Burgos se unió a Rivero Pino en el artículo Las masculinidades: una asignatura pendiente en los medios de comunicación, donde aseveran que:

\begin{abstract}
Hoy los medios continúan distorsionando los conceptos de masculinidades, metrosexualidad y homosexualidad, lo cual genera confusión en la sociedad actual, profundamente supeditada a dichos medios, lo cual muestra que son fuente y reflejo de injusticia y discriminación; sin embargo, resulta injusto que toda la responsabilidad recaiga sobre estos, pues es en la sociedad donde se construyen estas nociones. La ideología androcentrista se resiste a ser sustituida por relaciones de equidad y se solapa, se repliega, se metamorfosea en la subjetividad de comunicadoras y comunicadores, las ideologías profesionales, las rutinas productivas, las interpretaciones de la política informativa y en la toma de decisiones (Rivero Pino y Delgado Burgos, 2014: 239).
\end{abstract}

De la pluma del ensayista y crítico de arte Frank Padrón, nace Diferente. Cine y Diversidad Sexual, libro que se convierte en un texto necesario para justipreciar el buen cine internacional y cubano que promueve el (re)conocimiento de esas otredades eróticas que han sufrido incomprensión y discriminación.

Una sociedad mal educada en términos sexuales, explicada sexistamente, y que a su tradicional homofobia latina, suma otro agravante, la presencia del Sida con la correspondiente lectura de la mentalidad social y la prensa oficial achacándoselo solo a los gays; todos ellos siguen empañando -que no ocultando- la mirada hacia la comunidad de sujetos de la diversidad sexual cubana. La discusión sobre las opciones sexuales de cada cual solo tiene lugar en las zonas de lo clínico, la creación artístico-literaria y apenas en lo académico; sin que estas tres zonas se toquen entre sí ni se ocupen de interactuar con la amplia comunidad existente, lo cual explica acaso la falta de programas o estrategias sociales que reivindiquen la diversidad sexual y la inserten, sin más prejuicios -no siempre sexuales-, en un proyecto emancipador de la condición no heterosexual dentro de la sociedad (Padrón, 2014: 122).

La Oficina Nacional de Estadística e Información exhibe en su Encuesta sobre Indicadores de Prevención de VIH en el año 2013 las siguientes características de los Hombres que tienen Sexo con otros Hombres (HSH) de 12 a 49 años: 
Los HSH, estimados en alrededor de un cuarto de millón (257828), representan el $8.2 \%$ de los hombres cubanos y el $9.2 \%$ de los que han tenido relaciones sexuales. Más de la mitad $(58 \%)$ son bisexuales y un $5.3 \%$ practica sexo transaccional (...) En Santiago de Cuba los HSH representan un 8.1\% de la población (ONEI, 2015: 5).

Tal encuesta ignora por completo a lesbianas, bisexuales, intersexuales y transexuales. Importantísima es la Tesis de Doctorado "Estrategia para la integración social de las personas transexuales en el contexto actual de la sociedad cubana", de Mariela Castro Espín, donde se sistematizan evidencias sobre la existencia de procesos asociados a exclusión que afectan a transexuales y sus causas en la contemporaneidad, que les sirven de base para fundamentar su propuesta de integración social. La autora falla al tomar en consideración sólo las particularidades de la Capital, obviando las realidades de las otras provincias.

En 2015, desde el plano jurídico, el abogado Manuel Vázquez esclareció en su texto Derechos sexuales: algunas consideraciones teóricas para su estudio, leyes básicas que se violan a LGBTI, por ejemplo el Derecho a la información sobre sexualidad, fundamentada en el conocimiento científico; implica que tal información, a la que todas las personas tienen derecho a acceder, debe difundirse de modo amplio utilizando todas las vías posibles hacia la totalidad de la sociedad.

Las últimas ediciones del Simposio Nacional e Internacional de Masculinidad y VIH ofrecen un compendio de investigaciones realizadas a nivel provincial y nacional por profesionales y estudiantes de diversas disciplinas científicas. Muchas de estas investigaciones versan sobre homosexualidad y transexualidad masculina mediante estrategias educativas para la prevención de las ITS y el VIH/Sida, descripciones de conductas de riesgo ante la epidemia, estrategias para el cambio y la inserción social de los $\mathrm{HSH}$, percepciones y prácticas de personas transgénero. Asimismo ocurre con las líneas temáticas de las ponencias presentadas en la Jornada Científica Provincial de Sexualidad, Adolescencia y Juventud.

Varias tesis de grado, realizadas por estudiantes de Psicología y Sociología de la Universidad de Oriente, han abordado a LGBT desde diferentes enfoques. Nos referimos a:

-"Masculinidad y homosexualidad", de Nerlys Hernández Sánchez (2006).

-“Heterosexualidad y homosexualidad ¿una relación de amistad posible?", de Yanet Ricart Ponce (2006).

-"Los estilos de afrontamiento del sujeto homosexual de la tercera edad a la exclusión sociopolítica", de Daniel Alberto Lahera Leraiza (2010).

-"Manifestaciones sociales de la práctica de la prostitución en grupos de homosexuales varones. Un estudio sociológico en la ciudad de Santiago de Cuba" de Yadira Navarro Ruiz (2012). 
-"Satisfacción de transexuales santiagueros con los servicios de atención de salud" de Owen Rivas (2015).

-"Diagnóstico participativo con enfoque de género: propuesta de intervención para lesbianas en condición de internamiento" de Annie Aguilar Álvarez (2016).

La Tesis de Doctorado "La exclusión social en homosexuales masculinos. Realidades y alternativas a favor de la inclusión", realizada por Yamirka Robert Brady, señala a los medios de comunicación como ámbitos de exclusión y enmarca que

\begin{abstract}
Si bien es cierto que las instituciones mediáticas a partir de la década del 2000, desarticulan algunas prácticas sociales de exclusión, incorporando el tema homosexual en la programación habitual, reproducen otras formas de exclusión que se circunscriben a la escasa divulgación de actividades de la diversidad sexual en los medios y a la no inclusión de las manifestaciones de las homosexualidades en programas en los que las manifestaciones de la heterosexualidad se han vuelto frecuentes (2016: 93).
\end{abstract}

A la vez, Yamirka demuestra que los mensajes apuntan a la heterosexualidad hegemónica. Esta investigación es el antecedente más completo, cercano y actual a la nuestra.

En internet aparecen escasos estudios y artículos cubanos acerca de cómo los medios de comunicación abordan la diversidad sexual, dentro de estos puede mencionarse al ensayo “¿Qué dicen nuestros blogs sobre género y diversidad sexual?”, de la bloguera Sandra Álvarez. La internauta siguió el quehacer de diez bitácoras durante cuatro años, por ejemplo Paquito el de Cuba, Negra cubana tenía que ser, En 2310 y 8225, HXD y Discriminación Cero, este último pertenece al periodista santiaguero Reinaldo Cedeño. Sandra expresa que:

\footnotetext{
De todas las temáticas posibles en este nuevo medio, una de reciente emergencia en las redes cubanas es el tratamiento del género, la sexualidad y la diversidad sexual, lo cual en varias ocasiones va asociado a cierto activismo en el terreno de los derechos sexuales y reproductivos, y en otras a la prevención del VIH/Sida. Todas son iniciativas propias, alejadas de las formalidades que conlleva el tomar partido cada vez que se "sube un post" o se debate a propósito de la sexualidad en su sentido más amplio, y no siempre vinculado con la genitalidad. En el mismo sentido, tratan la diversidad sexual a partir del compromiso personal y en estricta consideración de su orientación sexual (Álvarez Ramírez, 2014).
}

También debemos hacer alusión a la serie de entrevistas Activismo LGBTIQ, un debate en Cuba, que parte de dos interrogantes: ¿Crees que el activismo LGBTIQ está cambiando la manera de hacer política en Cuba hoy? ¿Por qué? Realizada por el proyecto Arcoiris, reúne a voces reconocidas dentro del activismo como Alberto Roque, la afrofeminista Sandra Álvarez, 
el poeta Isbel Díaz Torres y el periodista Francisco Rodríguez "Paquito el de Cuba". El texto nos permite analizar el fenómeno de la lucha por los derechos sexuales desde las visiones y expectativas de sus protagonistas no heterosexuales.

En el Servicio de Noticias de la Mujer de América Latina y el Caribe (SEMlac) encontramos el comentario "La televisión mata a las lesbianas", de la periodista Karen Manzano, donde se plantea:

Desde finales de los 70 y hasta el 2016, el 35\% de las lesbianas que aparecen en las series norteamericanas muere. Es una cifra muy alta, pero para los que encuentren que no es suficiente justificación añadiré que las que no mueren no tienen un destino mucho más alentador. Solo un $16 \%$ tiene un final feliz. (...) La industria audiovisual penaliza las conductas "incorrectas". No hay nada aleatorio en la elección de las sentenciadas, casi siempre muere quien transgrede los códigos de lo aceptable (Manzano, 2016: 5).

Al revisar el discurso mediático cubano actual, se evidencia una limitante para el estudio y la visibilización de LGBTI que enfrentan también las investigaciones a nivel nacional dentro de las Ciencias Sociales: la separación del enfoque de género como relativo a lo femenino y a las problemáticas de las mujeres, de los análisis de masculinidad, dirigidos a los hombres.

\begin{abstract}
Aunque las investigaciones sobre género y comunicación social han ido creciendo en los últimos años, hay que señalar que son aún insuficientes y la mayoría se centran en la imagen de la mujer, pero muy pocas en la del hombre, y casi ninguna sobre receptoras y receptores. Lo realizado muchas veces se limita a usar la categoría género en una dimensión estadística (Rivero Pino y Delgado Burgos, 2014: 244).
\end{abstract}

Un buen número de autores y comunicadores insisten en mantener dos polos bien delimitados. Por un lado, abordan dentro de los estudios de género: la violencia hacia la mujer, la equidad, el embarazo en la adolescencia, los oficios y roles tradicionalmente asignados a hombres que hoy desarrollan las mujeres, la planificación familiar y el derecho a la licencia de paternidad. En el otro lado encontramos los estudios y eventos de masculinidades, donde son tópicos frecuentes el alcoholismo, la metrosexualidad, la transexualidad, la homosexualidad, el $\mathrm{VIH} /$ Sida, la homofobia, la transfobia, conductas violentas en hombres recluidos y la prostitución masculina.

Para los estudiosos cubanos el enfoque de género es un concepto o una concepción metodológica y epistemológica multidefinible, ya que quienes se acercan a la realidad cognoscitivamente lo hacen con miradas diferentes según sus profesiones y experiencias vitales. Unos estiman que hay que revisar la dicotomía que admite que sólo existen dos géneros, el del hombre y el de la mujer, porque ella también tiene un sesgo de las sociedades 
donde ha imperado la cultura patriarcal. Algunos abogan que debería incluirse a los transgénero, quienes han sido omitidos por esta cultura. La mayoría dice que es preciso diferenciar entre sexo, género y orientación sexual, y prácticamente todos afirman que es una vulgarización identificar la perspectiva de género con estudiar solamente a la mujer, sin compararla con el hombre.

De los autores que han analizado el fenómeno en cuestión, Ramón Rivero Pino se levanta con una de las voces más fuertes, críticas y certeras:

\begin{abstract}
El análisis de la problemática de género y su impacto en la vida social, desde el enfoque de los modelos hegemónico de masculinidad y feminidad, deja fuera otra gama de contradicciones que responden a otros aspectos genéricos, necesidades e intereses de los actores individuales y colectivos, es decir, estructuras y grupos sociales constituidos por hombres o mujeres que son exponentes de los modelos marginados de masculinidad y feminidad: lesbianas, gays, travestis, transexuales, intersexuales, hombres y mujeres del campo, no blanco(a)s, adulto(a)s, discapacitado(a)s... ¿Cuáles serán las expropiaciones históricas de masculinidad y feminidad de estos grupos, que se reproducen en los espacios sociales? ¿Cuál será el contenido de las distorsiones de las pautas culturales y de socialización de género instituidas, que se dan en estos tipos de agrupamientos? Las ciencias sociales y humanísticas cubanas tienen, como deuda, la indagación más sistematizada, integral e integradora de estos aspectos (Rivero Pino, 2014: 6).
\end{abstract}

A modo de resumen, declaramos que los estudios referidos han abierto el camino en la búsqueda de información y la reflexión acerca de LGBTI cubanos. Se observa en ellos una tendencia hacia los enfoques enunciativos y descriptivos, con menor visibilización de los prospectivos y propositivos. Dentro de sus fortalezas pueden señalarse: la identificación de malestares sociales asociados a prácticas tradicionales homofóbicas y sexistas; el interés en sensibilizar acerca de la importancia del tema y la necesidad de transformar el estado de cosas existente.

Sin embargo, se caracterizan por ser aislados, por la insuficiente integración entre sí, lo que puede asociarse a la ausencia de transdisciplinariedad y multidisciplinariedad en sus enfoques. Creemos importante y necesario implementar vías de integración, la socialización de resultados y la colaboración personal e institucional.

De manera general, ha sido insuficiente la reflexión acerca del reconocimiento de LGBTI. Resulta evidente que el machismo y el sexismo existentes a nivel social también están presentes en la producción académica nacional, pues abundan los estudios sobre la población masculina transexual y con orientación homo-bisexual. Apenas se abordan las características, exclusiones, contextos y activismo de las mujeres lesbianas, bisexuales, transexuales e intersexuales. 
Tanto la investigación científica como los medios de difusión masiva poseen un potencial enorme y sumamente importante para llevar a cabo un cambio en las imágenes que hoy se construyen de LGBTI, incluso para reclamar políticas públicas estatales y abrir espacios de comunicación más igualitarios, inclusivos, representativos. Esto es un paso imprescindible para trabajar hacia una convivencia más equitativa, justa y pacífica.

\section{Notas}

(1) Publicada en la Gaceta Oficial el 12 de mayo de 1974, que adicionaba al artículo 2 de la Ley 1166 de 23 de septiembre de 1964 el inciso j.

(2) Sexología y Sociedad es la publicación especializada del CENESEX, se trata de una revista de divulgación científica nacida en 1994, vanguardia en el abordaje de la transexualidad cubana.

\section{Bibliografía}

AA. VV. (2013). VI Jornada Contra la Homofobia. Artículos de prensa (compilación). Revista Sexología y Sociedad, 19(51), pp. 56-68.

Adam, B. (2005). Cuidados, intimidad y relaciones entre sexos iguales en el siglo XXI. Revista Sexología y Sociedad, 11(28), pp. 21-32.

Agramonte Machado, A. (2008). Intersexualidad y estigma social. Revista Sexología y Sociedad, 14(36), pp. 18-23.

Alfonso Rodríguez, A. y Rodríguez Lauzurique, R. M. (2009). Familia y personas transexuales: una relación al desnudo. Revista Sexología y Sociedad, 15(40), pp. 32-39.

Álvarez Ramírez, S. (5 de agosto de 2014). ¿Qué dicen nuestros blogs sobre género y diversidad sexual? Recuperado de http://www.cubasolidaridad.org/news/show/iquedicen-nuestros-blogs-sobre-genero-y-diversidad-sexual-/

Álvarez, C. (1996). Educación Sexual en Cuba, reseña histórica. Revista Sexología y Sociedad, 2(6), pp. 25-29.

Athenea Digital y Van Dijk, T. (2002). El análisis crítico del discurso y el pensamiento social. Athenea Digital, pp. 18-24.

Ávalos Boitel, O. E. (2009). Homosexualidad masculina en el juego del poder: Hegemonía o subordinación? La Habana: Manuscrito.

Bombino Companioni, Y. (2013). Estudios sobre sexualidad y género: su visualización en la Revista Sexología y Sociedad. Revista Sexología y Sociedad, 19(51), pp. 23-29.

Bourdieu, P. (2004). La lógica de los campos. En A. Basail Rodríguez y Álvarez Durán, D. Sociología de la Cultura (pp. 159-172). La Habana: Editorial Félix Varela. 
Cárreaga Pérez, G. (2003). Aproximaciones para el estudio de la diversidad sexual. Revista Sexología y Sociedad, 9(22), pp. 10-13.

Castro Espín, M. (2003). El sexo como juez universal del ser humano. Revista Sexología y Sociedad, 9(23), pp. 4-9.

Castro Espín, M. (2008). La atención integral a transexuales en Cuba y su inclusión en las políticas sociales. Revista Sexología y Sociedad, 14(36), pp. 4-10.

Castro Espín, M. (2011). La Educación Sexual como Política de Estado en Cuba desde 1959. Revista Sexología y Sociedad, 17(45), pp. 4-13.

Castro Espín, M. (2014). Tesis de Doctorado Estrategia para la integración social de las personas transexuales en el contexto actual de la sociedad cubana. La Habana: Universidad de La Habana.

Castro, F. (1992). Un grano de maíz. La Habana: Publicaciones del Consejo de Estado.

Centro de Estudios Estratégicos para la Democracia Proactiva José I. García Hamilton (20 de enero de 2016). Informe Anual del CEEDPA sobre violaciones de los Derechos Humanos en Cuba (2015). Recuperado de http://ernestoverarod.blogspot.com/2016/01/informe-anual-del-ceedpa-sobre.html

Chacón, L. (2004). Estudio del comportamiento sexual de Hombres que tienen Sexo con otros Hombres en Ciudad de La Habana. Revista Sexología y Sociedad, 10(24), pp. 11-17.

Cordero Velásquez, T. (2011). ¿Cómo se piensa lo queer en América Latina? Comentarios desde el Sur. Íconos Revista de Ciencias Sociales, pp. 129-135.

Delgado Burgos, R. C. (2010). La cualidad comunitaria y las formas históricas de masculinidades en el discurso periodístico del semanario Invasor, de la provincia de Ciego de Ávila. (Tesis de Maestría). Universidad Central de Las Villas, Santa Clara.

Diamond, M. (2003). Componentes básicos de la sexualidad humana. Revista Sexología y Sociedad, 9(23), pp. 16-25.

Díaz Álvarez, M. T. (2000). La dimensión de Género en los medios de comunicación social. Revista Sexología y Sociedad, 6(15), pp. 7-10.

Díaz Álvarez, M. T. (2012). Hombres que se miran. Revista Sexología y Sociedad, 18(49), pp. 14-22.

Díaz Bravo, C. (2007). La Educación de la Sexualidad en un mundo mediático. Reflexiones desde Cuba. Revista Sexología y Sociedad, 13(35), pp. 26-29.

Durkheim, E. (1898). Representations individuelles et répresentations collectives. Revue de Méthaphysique et Morale, 6, pp. 273-302.

El Amante del Periódico (10 de abril de 1791). Carta crítica del hombre-muger. Papel Periódico de La Habana.

Fowler, V. (1998). La maldición. Una historia del placer como conquista. La Habana: Editorial Letras Cubanas. 
García Franco, R. (2007). La sexualidad en el misterio del ser humano. Cárdenas: Ediciones Centro Cristiano de Reflexión y Diálogo.

Giddens, A. (2000). Sociología. Madrid: Alianza Editorial.

Giner, S. y Lamo de Espinosa, E. (2001). Diccionario de Sociología. Madrid: Alianza Editorial.

Guasch Andreu, Ó. (2012). Masculinidades: teorías y experiencias de discriminación. Revista Sexología y Sociedad, 18(48), pp. 4-10.

Hernández Batista, A. (2006).¿Masculinidad o Masculinidades? Un estudio de algunos lugares de socialización homosexual. (Trabajo de Curso). Universidad de La Habana, La Habana.

Jodelet, D. (1986). La representación social: fenómenos, conceptos y teoría. Barcelona: Editorial Paidós.

Kindelán Arias, Z. (2010). Algunas consideraciones sobre la actuación jurídica ante la solución de los conflictos de las personas LGBT. Una mirada crítica desde Cuba. Revista Sexología y Sociedad, 16(44), pp. 32-39.

Lario, M. (2008). La representación de la inmigración y de los inmigrantes en la prensa y en la radio: estado de la cuestión. En Bañón, A. y Fornieles, J. Manual sobre comunicación e inmigración (pp. 195-213). San Sebastián: Editorial Gakoa.

MacMillan, G. y Yunge Decaud, P. (2002). Experiencia quirúrgica en transexualismo de psiquis femenina. Revista Sexología y Sociedad, 8(18), pp. 10-15.

Manzano, K. (2016). La televisión mata a las lesbianas. Revista Servicio de Noticias de la Mujer de América Latina y el Caribe (SEMlac) Género y Comunicación, XI(4).

Morales, S. (2001). El negro y su representación social. La Habana: Editorial de Ciencias Sociales.

Moreno Castañeda, R. (2013). Ni vigilar ni castigar: un análisis del discurso en la Revista Sexología y Sociedad. (Trabajo de Diploma). Universidad de Oriente, Santiago de Cuba.

Moreno Fraginals, M. (1978). El Ingenio. Complejo económico social cubano del azúcar. La Habana: Editorial de Ciencias Sociales.

Moscovici, S. (1979). El Psicoanálisis, su imagen y su público. Buenos Aires: Editorial Huemul.

Moscovici, S. (1981). On social representations. En Forgas, J. Social Cognition perspectives on everyday knowledge (pp. 181-209). London: Academic Press.

Mott, L. (2001). Etno-historia de la homosexualidad en América Latina. Historia y Sociedad, pp. 123-145.

Moya Richard, I. (2004). Lo gay también vende. Revista Sexología y Sociedad, 10(26), pp. 1621. 
Moya, I. (2009). Sobre una gorda sin sentimientos, la devoradora felina y otras. En Hernández, C. N. Género. Selección de Lecturas Complementarias (pp. 126-130). La Habana: Editorial Caminos.

Núñez Sarmiento, M. (2004). Los estudios de género en Cuba y sus aproximaciones metodológicas, multidisciplinarias y transculturales (1974-2001). Revista Cuba Literaria, pp. 9-15.

Oficina Nacional de Estadística e Información (2015). Encuesta sobre Indicadores de Prevención de VIH en el año 2013. La Habana: ONEI.

Padrón, F. (2014). Diferente. Cine y diversidad sexual. La Habana: Ediciones ICAIC.

Páez, D. (1987). Pensamiento, individuo y sociedad: Cognición y representación social. Madrid: Editorial Fundamentos.

Pereira Ramírez, R. (2008). El derecho a la libre orientación sexual: un derecho sexual sin protección legal en Cuba. Revista Sexología y Sociedad, 14(36), pp. 11-17.

Perera, M. (1999). A propósito de las representaciones sociales. Apuntes teóricos, trayectoria y actualidad. La Habana: CIPS.

Perera, M. (2005). Sistematización crítica de la Teoría de las Representaciones Sociales. (Tesis de Doctorado). Universidad de La Habana, La Habana.

Pérez Cruz, F. (1999). Homosexualidad, homosexualismo y ética humanista. La Habana: Editorial de Ciencias Sociales.

Pino, A. J. (2009). El enfoque de género en los medios de difusión. La experiencia de Tele Cubanacán. (Tesis Doctoral). Universidad Central de Las Villas, Santa Clara.

Proyecto Arcoiris (12 de septiembre de 2015). Activismo LGBTIQ, un debate en Cuba. Recuperado de http://proyectoarcoiris.cubava.cu/2015/09/cuba-activismo-Igbtiq/

Regina Festa, M. V. (2003). Género y Comunicación: Las mujeres en los medios masivos y en la agenda política. Argentina: Fundación Friedrich Ebert.

Rivero Pino, R. (2014). Pensar las masculinidades. La Habana: Editorial CENESEX.

Rivero Pino, R. y Delgado Burgos, R. (2014). Las masculinidades: una asignatura pendiente en los medios de comunicación. En Rivero Pino, R.. Pensar las masculinidades (pp. 239255). La Habana: Editorial CENESEX.

Robert Brady, Y. (2013). Homosexuales en la ciudad Santiaguera. Un enfoque de análisis desde la Sociología. Revista Santiago, pp.136-158.

Robert Brady, Y. (2016). La exclusión social en homosexuales masculinos. Realidades y alternativas a favor de la inclusión. (Tesis Doctoral). Universidad de Oriente, Santiago de Cuba.

Rodríguez Cárdenas, M. (2008). La socialización de varones homosexuales. Un estudio de caso en Santa Clara. (Trabajo de Diploma). Universidad Central de Las Villas, Santa Clara. 
Rodríguez, R. (2006). La sexualidad en el atardecer de la vida. Santiago de Cuba: Editorial Oriente.

Rodríguez, R.; Alfonso, A. y García, C. (2007). Trastorno de identidad de género y personas transexuales. Experiencias de atención en Cuba. Revista Sexología y Sociedad, 13(33), pp. 13-18.

Roque Guerra, A. (2011). Diversidad Sexual en las políticas públicas en Cuba: Avances y Desafíos. Revista Sexología y Sociedad, 17(45), pp. 34-39.

Salvador Giner. (2003). Teoría Sociológica Moderna. Barcelona: Editorial Ariel.

Sierra Madero, A. (2002). La nación sexuada. Relaciones de género y sexo en Cuba (18301855). La Habana: Editorial de Ciencias Sociales.

Sierra Madero, A. (2003). La policía del sexo: La homofobia durante el siglo XIX en Cuba. Revista Sexología y Sociedad, 9(21), pp. 21-31.

Taybo, G. y González, A. (1998). Estudio del imaginario social de la masculinidad en hombres jóvenes. (Trabajo de Diploma). Universidad de Oriente, Santiago de Cuba.

Vázquez, M. (2015). Derechos sexuales: algunas consideraciones teóricas para su estudio. La Habana: Editorial CENESEX.

Velandia Mora, M. (2007). De la identidad sexual como experiencia y concepto fijo a la Identidad Sexual como construcción vivencial y conceptual en la movilidad. Revista Sexología y Sociedad, 13(33), pp. 4-11. 